\title{
Inflammation-Induced Endothelial-to-Mesenchymal Transition
}

\section{A Novel Mechanism of Intestinal Fibrosis}

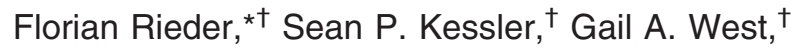 \\ Shardul Bhilocha, ${ }^{\dagger}$ Carol de la Motte, ${ }^{\dagger}$ \\ Tammy M. Sadler, ${ }^{\dagger}$ Banu Gopalan, ${ }^{\ddagger}$ \\ Eleni Stylianou, ${ }^{\dagger}$ and Claudio Fiocchi ${ }^{\star \dagger}$ \\ From the Department of Gastroenterology \& Hepatology, \\ Digestive Disease Institute, the Department of Pathobiology, ${ }^{\dagger}$ \\ Lerner Research Institute, and the Genomic Medicine Institute, ${ }^{\neq}$ \\ Cleveland Clinic Foundation, Cleveland, Obio
}

In addition to mesenchymal cells, endothelial cells may contribute to fibrosis through the process of endothelial-to-mesenchymal transition (EndoMT). We investigated whether human intestinal microvascular endothelial cells (HIMEC) undergo EndoMT and contribute to fibrosis in human and experimental inflammatory bowel disease (IBD). HIMEC were exposed to TGF- $\beta 1, I L-1 \beta$, and TNF- $\alpha$ or supernatants of lamina propria mononuclear cells (LPMC) and evaluated for morphological, phenotypic, and functional changes compatible with EndoMT. Genomic analysis was used to identify transcription factors involved in the transformation process. Evidence of in situ and in vivo EndoMT was sought in inflamed human and murine intestine. The combination of TGF- $\beta 1$, IL- $1 \beta$ and TNF- $\alpha$, or activated LPMC supernatants induced morphological and phenotypic changes consistent with EndoMT with a dominant effect by IL-1. These changes persisted after removal of the inducing agents and were accompanied by functional loss of acetylated LDL-uptake and migratory capacity, and acquisition of de novo collagen synthesis capacity. Sp1 appeared to be the main transcriptional regulator of EndoMT. EndoMT was detected in microvessels of inflammatory bowel disease (IBD) mucosa and experimental colonic fibrosis of Tie2-green fluorescent protein (GFP) reporter-expressing mice. In conclusion, chronic inflammation induces transdifferentiation of intestinal mucosal microvascular cells into mesenchymal cells, suggesting that the intestinal microvasculature contributes to IBD-associated fibrosis through the novel process of EndoMT. (Am J Patbol 2011, 179:2660-2673; DOI: 10.1016/j.ajpath.2011.07.042)

Intestinal fibrosis is a complication of inflammatory bowel disease (IBD) with serious clinical implications. ${ }^{1,2}$ It occurs in both Crohn's disease (CD) and ulcerative colitis (UC), in which fibrosis displays differential features depending on the distribution, degree, and duration of inflammation. ${ }^{1,2}$

Mesenchymal cells are primarily responsible for intestinal fibrosis. ${ }^{1,3}$ In response to pro-inflammatory signals, they become activated, expand in number, and increase secretion of extracellular matrix (ECM), which contributes to tissue remodeling and fibrosis. ${ }^{4}$ Sources of fibroblasts in the inflamed gut include migration from nearby areas, proliferation, differentiation from stellate cells, and recruitment from the bone marrow. ${ }^{1,5-8}$

Alternative mechanisms of fibrosis involve the differentiation and transformation of cells of nonmesenchymal origin. ${ }^{9-11}$ In inflamed organs, fibroblasts can be generated through epithelial-to-mesenchymal transition (EMT), ${ }^{12}$ a process whereby epithelial cells acquire fibroblast phenotype and function as result of the action of several factors, among which transforming growth factor $-\beta 1$ (TGF- $\beta 1$ ) is the best characterized. ${ }^{9,13}$ There is preliminary evidence that EMT occurs during fistula formation in CD patients and in experimental colitis. ${ }^{14,15}$

Endothelial-to-mesenchymal transition (EndoMT) is an additional form of transformation relevant to fibrosis. Transdifferentiation of endothelial cells into mesenchymal cells was originally described in experimental wound repair, in

Supported by NIH grants DK50984 and DK069854 (C.F.), the Deutsche Forschungsgemeinschaft (RI1735/2-1 to F.R.), and the Crohn's and Colitis Foundation of America (CCFA Ref \# 2308 to F.R.).

Accepted for publication July 25, 2011

Supplemental material for this article can be found at http://ajp. amjapthol.org or at doi: 10.1016/j.ajpath.2011.07.042.

Address reprint requests to Claudio Fiocchi, M.D., Department of Pathobiology, Lerner Research Institute, Cleveland Clinic Foundation, 9500 Euclid Avenue, Cleveland, OH 44195. E-mail: fiocchc@ccf.org. 
which inflammatory stimuli force the conversion of capillary endothelial cells into spindle-shaped granulation tissue cells. ${ }^{16}$ Bovine endothelial cells from aortic or pulmonary arteries differentiate into mesenchymal cells in vitro, ${ }^{17}$ and endothelial cells contribute to the pool of fibroblasts in murine models of cardiac, kidney, and lung fibrosis. ${ }^{18-20}$ As for EMT, TGF- $\beta 1$, tumor necrosis factor- $\alpha$ (TNF- $\alpha$ ) and IL- $1 \beta$ are the main drivers of EndoMT, suggesting mechanistic similarities between the two processes. ${ }^{13,19,21}$

The above observations, coupled with the presence of inducers of EndoMT in IBD tissues, suggest that EndoMT could play a pro-fibrogenic role in the gut. We provide evidence that human intestinal mucosal microvascular cells transdifferentiate into mesenchymal cells on exposure to recombinant inflammatory cytokines but also ex vivo native mediators produced by mucosal immune cells. We found IL-1 $\beta$ to be the main driver of EndoMT and detected in situ and in vivo evidence of EndoMT in human and murine inflamed intestine.

\section{Materials and Methods}

\section{Isolation and Culture of Intestinal Cells}

Surgically resected specimens were used for isolation of human intestinal microvascular endothelial cells (HIMEC), human intestinal fibroblasts (HIF), and lamina propria mononuclear cells (LPMC). All specimens were of colonic origin, and cells were isolated and cultured as previously reported. ${ }^{22-24}$

HIF were obtained as explants of surgically resected intestinal mucosa, grown to subconfluence in Dulbecco's minimal essential medium supplemented with $10 \%$ fetal bovine serum (FBS) and antibiotics, and then established as long-term cultures that were fed twice a week and subcultured at confluence. HIF are strongly $\alpha$-actin positive, vimentin positive, desmin positive, and CD68, CD31, and cytokeratin negative ${ }^{24-30}$; in addition, flow cytometry shows that HIF express CD73 (ecto-5'-nucleotidase) and CD105 (endoglin, a surface membrane glycoprotein part of the TGF- $\beta$ receptor complex). CD73 and CD105 are markers expressed by mesenchymal stem cells that are transmitted to their mesenchymal lineage descendents, such as muscle cells and fibroblasts. ${ }^{31} \mathrm{HIF}$ were used between passages 3 and 10 .

Isolation of HIMEC was performed as previously reported. ${ }^{22}$ This consisted of enzymatic digestion of intestinal mucosal strips followed by gentle compression to extrude endothelial cell clumps, which adhered to Petri plates precoated with fibronectin at $1 \mu \mathrm{g} / \mathrm{cm}^{2}$. After 5 to 14 days of culture, discernible islands of endothelial cells were released using a solution of $0.05 \%$ trypsin and 0.53 $\mathrm{mmol} / \mathrm{L}$ EDTA in calcium- and magnesium-free PBS. Suspended single cells were rinsed twice in PBS containing $2 \%$ FBS and stained with PE-mouse anti-human CD31 (PharMingen, San Diego, CA). CD31-positive cells were then sorted directly into a fibronectin-precoated well of a 24-well Costar plate using a BD FACS Aria machine (BD, San Jose, CA). Sorted cells were cultured in MCDB131 medium (Sigma, St. Louis, MO) supplemented with $20 \%$
FBS, antibiotics, heparin, and endothelial cell growth factor (Lonza, Walkersville, MD). ${ }^{22}$ HIMEC were used between passage 8 and 14. HIF and HIMEC cultures were maintained at $37^{\circ} \mathrm{C}$ in $5 \% \mathrm{CO}_{2}$, fed twice a week, and subcultured at confluence. LPMC were isolated from macroscopically involved and noninvolved, dysplasia-free bowel segments. ${ }^{23}$

Tissues were obtained from histologically normal large-bowel specimens from patients admitted for bowel resection because of malignant and nonmalignant conditions, including colon cancer, benign polyps, and diverticulosis. Involved and noninvolved CD and UC coIonic tissues were also obtained. A total of 28 specimens were used, including 10 controls, 9 UC, and 9 CD. All diagnoses were confirmed by clinical, radiological, endoscopic, and histological criteria. The Institutional Review Board and Institutional Animal Care and Use Committee of the Cleveland Clinic Foundation approved the human and animal studies, respectively.

\section{Cell Cultures}

HIMEC monolayers were cultured in six-well plates coated with fibronectin $(1 \mu \mathrm{g} / \mathrm{mL})$ or collagen I (6 $\mu \mathrm{g} /$ $\mathrm{cm}^{2}$ ) (Roche, Basel, Switzerland). Cells were exposed to individual cytokines or in combination (IL-1 $\beta 100 \mathrm{U} / \mathrm{mL}$; TNF- $\alpha 100 \mathrm{U} / \mathrm{mL}$; TGF- $\beta 1,5 \mathrm{ng} / \mathrm{mL}$; all from Peprotech, Rocky Hill, NJ) for 6 days unless otherwise stated. HIMEC medium was changed every 3 days. Lamina propria mononuclear cells (LPMC) supernatants were generated by culturing $1 \times 10^{6}$ cells $/ \mathrm{mL}$ for 72 hours, alone or in plates coated with OKT-3 $(10 \mu \mathrm{g} / \mathrm{mL})$ plus soluble CD28 (1 $\mu \mathrm{g} / \mathrm{mL}$; Ancell, Bayport, MN) and LPS (100 ng/mL), and samples were stored at $-80^{\circ} \mathrm{C}$ until use. For LPMC cytokine neutralization experiments optimal concentrations of IL-1RA ( $1 \mu \mathrm{g} / \mathrm{mL})$, anti-TGF- $\beta 1(10 \mu \mathrm{g} / \mathrm{mL})$ and anti-TNF- $\alpha$ (10 $\mu \mathrm{g} / \mathrm{mL}$; all R\&D) were used.

\section{Electron Microscopy}

For transmission electron microscopy (TEM) analysis, HIMEC and HIF were cultured on 4-well Permanox-Slides (Nunc, Rochester. NY, USA) as confluent monolayers and treated with the combination of TGF- $\beta 1$, TNF- $\alpha$ and $\mathrm{IL}-1 \beta$ (see above) for 9 days. At the end of the incubation period cells were washed with PBS, immersed in $2 \%$ glutaraldehyde, and washed twice in PBS and postfixed with $1 \%$ osmium tetroxide in PBS for 1 hour. After two ten minute washes in double-distilled water, specimens were stained in $0.25 \%$ uranyl acetate overnight. After 24 hours, the specimens were washed with water and dehydrated through a graded series of alcohol and propylene oxide washes. Each sample was infiltrated sequentially with 2:1 and 1:1 propylene oxide-EPON for 4 hours, incubated overnight with $100 \%$ EPON, transferred to fresh EPON, and embedded and polymerized at $60^{\circ} \mathrm{C}$ for 24 hours. Thin sections were collected on copper grids, stained with uranyl acetate and lead citrate, and viewed using a Phillips CM-12 transmission electron microscope. At least 20 individual cells per condition were analyzed. 


\section{Immunofluorescence}

A total of $80,000 \mathrm{HIMEC} /$ well were seeded onto glass 8-well chamber slides (Nunc, Naperville, IL) coated with $1 \mu \mathrm{g} / \mathrm{mL}$ fibronectin (Roche). After culture under various conditions, slides were rinsed in PBS and fixed with either ice-cold acetone or $4 \%$ paraformaldehyde at room temperature (RT) for 10 minutes. Before application of the primary antibody, fixed cells were blocked with 3\% FBS in PBS. All primary and secondary antibodies were diluted in 1\% FBS. For endothelial and mesenchymal markers monoclonal rabbit anti-human von Willebrand factor (factor VIII-associated antigen) antibody (Santa Cruz, Los Angeles, CA) was used at 1:100 dilution; mouse anti-human platelet endothelium cell adhesion molecule 1 (PECAM-1/CD31; Santa Cruz) at 1:100 dilution; mouse anti-human vascular endothelial cadherin (VE-cadherin; Santa Cruz) at 1:100 dilution; rabbit anti-human S100A4 (Dako, Carpinteria, CA) at 1:500 dilution; mouse antihuman $\alpha$-smooth muscle actin (Sigma) at 1:25 dilution; mouse anti-human desmin (Abcam, Cambridge, MA) at a 1:100 dilution; and collagen 1 (Rockland, Gilbertsville, PA) at a 1:500 dilution. The respective antibody isotypes (Sigma and Santa Cruz) were used as controls for the primary antibody. After 2-hour incubation with the primary antibody at room temperature, slides were rinsed three times with PBS and the AlexaFluor 488 or AlexaFluor 594 antibody (Molecular Probes, Eugene, OR) was added at a dilution 1:500 for 1 hour at $37^{\circ} \mathrm{C}$. AF488 coupled Phalloidin (AlexaFluor) was used at 1:40 dilution. For pericyte markers we used mouse anti-human NKI/M6 (Santa Cruz) and rabbit anti-human NG2 (Chemicon, Temecula, CA) at a concentration of 1:100. Anti-3G5 IgM was purified from supernatants of the $3 G 5$ hybridoma line ATCC CRL 1418 (American Type Culture Collection, Manassas, VA). For nuclear counterstaining Vectashield mounting medium with DAPI (Vector Laboratories, Burlingame, CA) was used to counterstain nuclei.

\section{Dil-Acetylated Low Density Lipoprotein-Uptake}

HIMEC were treated with a combination of IL-1 $\beta 100$ $\mathrm{U} / \mathrm{mL}, \mathrm{TNF}-\alpha 100 \mathrm{U} / \mathrm{mL}$ and TGF- $\beta 15 \mathrm{ng} / \mathrm{mL}$ for up to 20 days. At the end of the incubation period monolayers were washed, Dil-acetylated low-density lipoprotein (DilAc-LDL) (Biomedical Technologies, Stoughton, MA) added at a concentration of $10 \mu \mathrm{g} / \mathrm{mL}$ for 4 hours at $37^{\circ} \mathrm{C}$, cells were washed again and LDL uptake was assessed by fluorescence microscopy.

\section{Immunostaining and Analysis of Intestinal Microvasculature}

Immunostaining was performed as previously described. ${ }^{26}$ Briefly, paraffin-embedded intestinal sections of histologically normal control and IBD-involved colonic mucosa were cut at 3- $\mu \mathrm{m}$ thickness, deparaffinized then hydrated, blocked for endogenous peroxidase using 3\% $\mathrm{H}_{2} \mathrm{O}_{2} / \mathrm{H}_{2} \mathrm{O}$, and subsequently subjected to microwave epitope enhancement using a Dako Target retrieval solution (Dako) at $\mathrm{pH}$ 10.00. Nonspecific binding was blocked with $3 \%$ FBS for 1 hour. Incubation with a primary antibody rabbit anti-human von Willebrand factor (Santa Cruz) was performed at 1:50 dilution and for $\alpha$-smooth muscle actin (Sigma) at 1:100 dilution for 1 hour at room temperature. Slides were rinsed three times with PBS and the AlexaFluor 488 or 594 antibody (1:500) applied for 1 hour at $37^{\circ} \mathrm{C}$. For nuclear counterstaining Vectashield mounting medium with DAPI (Vector Laboratories) was used. In addition, hematoxylin/eosin and Masson trichrome stains were performed following standard procedures. The murine colonic tissue was treated accordingly: colons were fixed in $10 \%$ buffered formalin and embedded in paraffin. Paraffin-embedded colon sections were cut and then stained by the Hematoxilin and Eosin (H\&E) and Masson's trichrome method. For staining of the paraffin-embedded colonic cross sections, chicken anti-GFP (Abcam), goat-anti CD31 (Santa Cruz), and mouse anti- $\alpha$-smooth muscle actin (Sigma) (all three at 1:100 dilution) and the respective AlexaFluor 488 or 594 labeled secondary antibodies were used. For the murine colonic section also frozen sections were used. Slides were analyzed using an Olympus microscope and ImagePro software (Media Cybernetics, Bethesda, MD).

\section{Immunoblotting}

Protein extraction was performed using a lysis buffer containing $50 \mathrm{mmol} / \mathrm{L}$ Tris $\mathrm{pH} 7.5,150 \mathrm{mmol} / \mathrm{L} \mathrm{NaCl}$, $1 \%$ Triton $\mathrm{X}-100,0.1 \%$ SDS, $1 \%$ Na-deoxycholate, and $1 \%$ protease and phosphatase inhibitor cocktail (Sigma). The concentration of proteins in each lysate was measured using the Bio-Rad protein assay (BioRad Laboratories, Hercules, CA) according to manufacturer's recommendations. Immunoblotting was performed as previously described. ${ }^{26}$ Equivalent amounts of proteins $(20 \mu \mathrm{g})$ were fractionated on a $6 \%$ or $8 \%$ Tris-glycine gel and electrotransferred to a PVDF membrane (Millipore, Billerica, MA). Nonspecific binding was blocked by incubation with $5 \%$ milk in $0.1 \%$ Tween 20/Tris-buffered saline (Fisher Scientific, Hanover Park, IL) for 30 minutes., followed by overnight incubation at $4^{\circ} \mathrm{C}$ with the primary antibody(s). CD31 (Santa Cruz) was used at a dilution of 1:1000; VE-cadherin (Santa Cruz) at 1:1000; vimentin (BD Bioscience, San Jose, CA) at 1:2000; N-cadherin (Santa Cruz) at 1:300; fibronectin (BD) at 1: 2000; collagen I (Rockland, Gilbertsville, PA) at 1:500; desmin (Abcam) at 1:1000; $\alpha$-SMA at 1:250; and GA3DH (Trevigen, Gaithersburg, MD) at 1:2000. Membranes were washed six times with $0.1 \%$ Tween 20/Tris-buffered saline, incubated with the appropriate horseradish peroxidase-conjugated secondary antibody (Sigma), washed again, and incubated with the chemiluminescent substrate (Super Signal; Pierce, Rockford, IL) for 5 minutes, after which they were exposed to film (Kodak). Densitometric analysis was carried out with a Bio-Rad Universal Hood 2 imaging system (Hercules, CA) by calculating the intensity of the band of the specific protein of interest to that of GAPDH corrected for background. Significant variability in gel loading was assessed by calculating the 
degree of variability among the different bands of GAPDH expression in the same gel.

\section{Migration Assays}

Migration assays were performed in the modified 48well Boyden chamber as described previously?: a polycarbonate filter (12- $\mu \mathrm{m}$ pore size, polyvinylpyrrolidone-free, NeuroProbe, Gaithersburg, MA) divided the chamber into upper and lower compartments. Each chemoattractant was placed into the wells of the lower compartment in replicates of three diluted in MCDB with $5 \%$ FBS. A total of $20,000 \mathrm{HIMEC}$ or $\mathrm{HIF} /$ well in MCDB with $5 \%$ FBS were seeded into the wells of the upper compartment of the Boyden chamber, which was then incubated at $37^{\circ} \mathrm{C}$ in $5 \% \mathrm{CO}_{2}$ atmosphere. After 18 hours the filter was removed, and the nonmigrated cells on the upper side of the filter were taken off with cotton-tipped swabs. The migrated cells on the lower side of the filter were fixed and stained with a Hemacolor staining kit (Merck, Darmstadt, Germany) and counted in high-power fields of view at a 630-fold magnification. Each experiment was performed at least in triplicate, and at least four fields were counted per well.

\section{Quantitative RT-PCR}

Selected genes relevant to cell differentiation and transformation that were regulated in the array data were confirmed by quantitative reverse transcription-polymerase chain reaction (qRT-PCR). Eight independent HIMEC preparations were incubated with or without IL-1 $\beta 100$ $\mathrm{U} / \mathrm{mL}$, TNF- $\alpha 100 \mathrm{U} / \mathrm{mL}$ and TGF- $\beta 15 \mathrm{ng} / \mathrm{mL}$ for 6 days. Total RNA was isolated and purified as above, and reverse transcription and quantitative PCR performed according to manufacturer's instructions (Applied Biosystems, Foster City, CA). For the respective genes we used assay kits for COL1A2/collagen 1 (Hs00164099_m1), TNC/tenascin (Hs01115664_m1), NID1/nidogen (Hs00159600_m1), S100A4/FSP-1 (Hs00243202_m1) and vWF/von Willebrand factor (Hs00169795_m1). Relative differences were calculated using the comparative threshold cycle method (ddCt) by normalizing to CT values of GAPDH (reference gene). For the persistence of HIMEC transformation and cytokine neutralization experiments, RNA was extracted (RNEasy Miniprep kit, Qiagen) following the manufacturer's protocol. qRT-PCR was performed on cDNA (synthesized with iScript cDNA Synthesis Kit, Biorad) with iQ Sybr Green Supermix (Biorad) and genespecific primers. GAPDH was used as the reference gene and the Pfaffl method was used to calculate fold changes in treated versus untreated samples. ${ }^{32}$ The forward and reverse primer sequences were as follows: for vWF (accession number NM_00055): 5'-GTGGTTGGTGGATGTCACAG-3' (nt 32-51) and 5'-GCAAATCTGGCAGGAATCAT-3' (nt 270-254) and for Col1A2 (accession number NM_000089.3): 5'-GCCCCCCAGGCAGA GA-3' (nt 614-629) and 5'-CCAACTCCTTTTCCATCATACTGA-3' (nt 731-708).

\section{Microarray Analysis}

Four independent HIMEC isolates were cultured with or without TGF- $\beta 1, \mathrm{IL}-1 \beta$, and TNF- $\alpha$ for 6 days. Total RNA was isolated and purified with the RNeasy Mini kit (Qiagen), and reverse transcribed into cRNA and biotin-UTP labeled using the Illumina TotalPrep RNA Amplification Kit (Ambion, Austin, TX). cRNA was quantified by nanodrop spectrophotometry and quality analyzed on a $1 \%$ agarose gel. cRNA was hybridized to the Illumina HumanRef-8 v2 Expression BeadChip (San Diego, CA) at the Cleveland Clinic Genomics Core facility. Statistical and functional analyses of gene expression data were performed by the Integrative Genomics Analysis Core facility. The raw gene expression datasets were processed to remove outliers, log2 transformed, and quantile normalized using $\mathrm{R}$ lumi software. ${ }^{33}$ Both raw $P$ values and FDR adjusted $P$ values were calculated. ${ }^{34}$ Genes that satisfied the FDR $P$ value threshold of $<0.05$ or raw $P$ value of $<0.001$ and fold change threshold of 1.5 were identified as significant for the functional pathway and network analysis. Gene regulatory networks were generated using MetaCoreTM analytical suite version 5.2 build 17389 (GeneGo, St Joseph, MI). ${ }^{35-37}$

\section{Mice}

Adult male and female FVB mice carrying GFP driven by the endothelial-specific Tie2 promoter (Tie2-GFP) were originally purchased from the Jackson Laboratory (Bar Harbor, ME) and subsequently bred in our biomedical research unit. Animals were housed, and husbandry and euthanization were conducted according to Institutional Animal Care and Use Committee-approved protocols.

\section{Induction of Chronic Inflammation-Mediated Murine Colonic Fibrosis}

Chronic murine colitis was induced by weekly administration of increasing doses of trinitrobenzene sulfonic acid (TNBS; Sigma-Aldrich) as previously described (starting dose of $3 \mathrm{mg}$ in $45 \%$ ethanol). ${ }^{38}$ Mice were lightly anesthetized with isoflurane and then administered TNBS/ethanol, ethanol, or PBS per rectum via a 3.5- $\mathrm{F}$ catheter equipped with a $1-\mathrm{mL}$ syringe; the catheter was advanced into the rectum until the tip was 4 $\mathrm{cm}$ proximal to the anal verge, at which time the TNBS was administered in a total volume of $150 \mu \mathrm{L}$. To ensure distribution of TNBS within the entire colon and cecum, mice were held in a vertical position for 30 seconds after the intrarectal injection.

\section{Statistical Analysis}

Data were analyzed by Stat View software (SAS Institute, Cary, NC) using analysis of variance (analysis of variance) for independent groups. Repeated measures for the same subject were analyzed by using Student's paired $t$-test. Values were expressed as mean \pm SEM, and statistical significance was set at $P<0.05$. 


\section{Results}

\section{Pro-Inflammatory Cytokine-Induced Morphological Changes in HIMEC}

We obtained HIMEC free of any other contaminating cell types by flow-cytometric sorting of CD31-positive cells immediately after isolation. Repeated flow cytometric analysis confirmed the absolute purity of HIMEC as late as 20 passages. HIMEC lacked CD45, CK20 and $\alpha$-SMA mRNA, failed to display $\alpha$-SMA or fibroblast-specific protein (FSP) -1 by immunostaining, and $>99 \%$ incorporated DilAc-LDL in freshly isolated and late passage cultures (not shown). Long-term cultures of HIMEC (up to passage 20, approximately equivalent to 5 months) show no changes in morphology, viability, surface markers, and they do not show evidence of spontaneous transformation or death. Typical endothelial cell morphology persisted throughout the duration of all experiments and $\alpha$-SMA-positive cells were never noted at any passage in any culture.

To induce EndoMT, HIMEC were treated with TGF$\beta 1^{18,19}$ as well as IL-1 $\beta$ and TNF- $\alpha$. Morphological changes were observed after exposure to individual cytokines, but the most dramatic changes, ie, marked increase in size and acquisition of spindle-shaped morphology, were observed when the three cytokines were combined (day 6) (Figure $1 \mathrm{~A})$. These changes persisted for at least 20 days after cytokine removal (not shown). Of note, adding TGF- $\beta 1$ alone at concentrations ranging from 0.001 to $10 \mathrm{ng} / \mathrm{mL}$ for up to 30 days failed to induce HIMEC morphological changes. HIMEC monolayers exposed to the cytokines used to induce EndoMT eg, TGF- $\beta 1$, TNF- $\alpha$, and IL- $1 \beta$, alone or in combination, maintained confluence, exhibited the same viability of nontransformed HIMEC, and contained only trivial amounts of cellular debris, which was comparable among cultures exposed to individual cytokines or their combinations.

\section{Phenotypic Changes in Transformed HIMEC}

HIMEC treated with TGF- $\beta 1, \mathrm{IL}-1 \beta$ and TNF- $\alpha$ acquired a spindle-shaped morphology correlated with loss of CD31, vascular endothelial (VE)-cadherin, and von Willebrand Factor (vWF) (Figure 1B). This loss was accompanied by rearrangement of the F-actin cytoskeleton: while untreated HIMEC showed a weak and disorganized expression of F-actin fibers, transformed cells exhibited a marked increase in stress fibers organized longitudinally as seen in human intestinal fibroblasts (HIF) (Figure 1B). ${ }^{24}$ Importantly, acquisition of $\alpha$-SMA and FSP-1 also occurred (Figure 1B). Consistent with the morphological changes, TGF- $\beta 1$ alone for up to 30 days failed to alter the expression of endothelial markers (not shown), but induction of $\alpha$-SMA was only observed if TGF- $\beta 1$ was present (Figure 1B), indicating that TGF- $\beta 1$ was necessary but insufficient for complete HIMEC transformation.

To assess whether morphological and phenotypic transformation was accompanied by alterations at the ultrastructural level, transformed, and nontransformed HIMEC were compared with HIF by electron microscopy. Transformed HIMEC displayed an elongated body similar
A
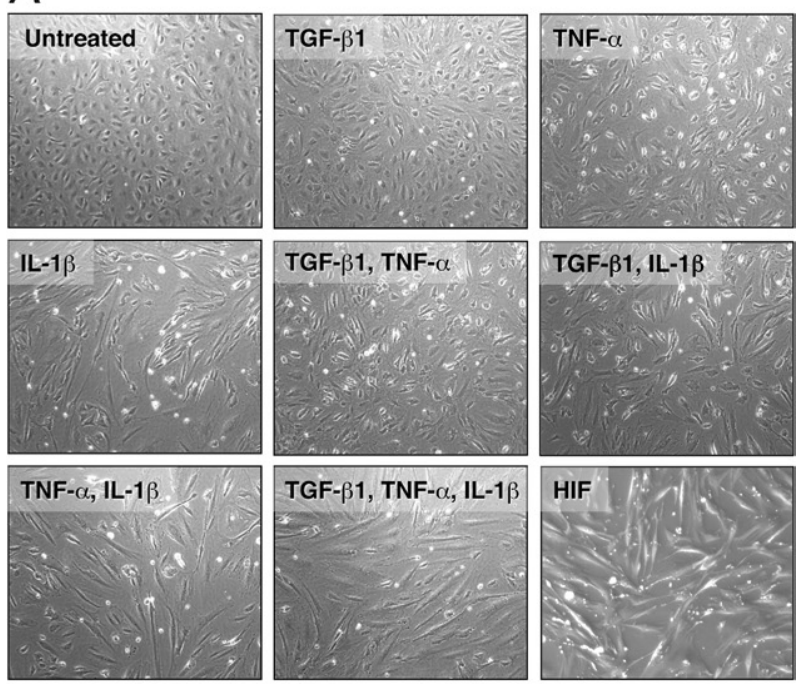

B
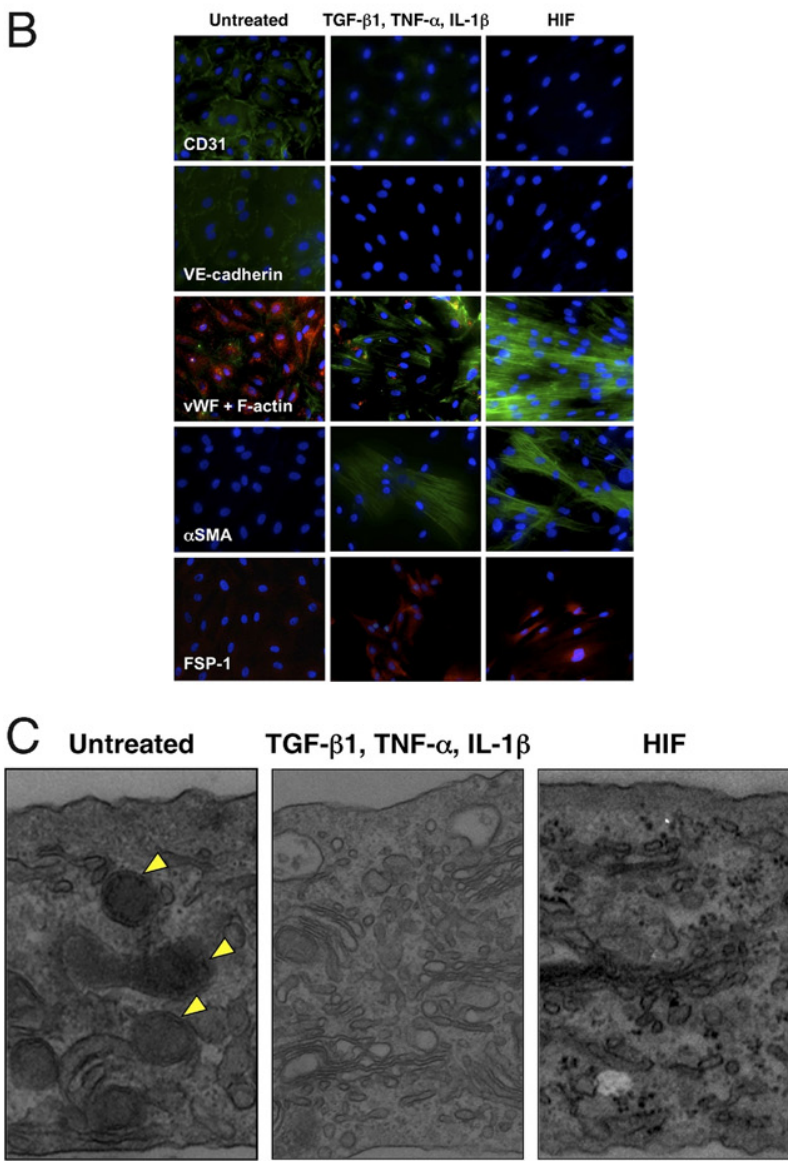

Figure 1. Morphological, phenotypic and ultrastructural changes in transformed HIMEC. A: HIMEC were left untreated or exposed to TGF- $\beta 1$, TNF- $\alpha$, and IL- $1 \beta$, alone or in combination, for 6 days. HIF served as controls for mesenchymal cell phenotype. Figure is representative of 20 experiments. B: Incubation with combined TGF- $\beta 1$, TNF- $\alpha$, and IL- $1 \beta$ induced loss of CD31 (green), VE-cadherin (green), and vWF (red), all of which were absent in HIF. A parallel acquisition of the fibroblast markers $\alpha$-SMA (green) and FSP-1 (red) occurred. Nuclei were counterstained with DAPI (blue). Immunofluorescence images are representative of seven experiments. C: Electron micrographs of untreated HIMEC, transformed HIMEC and HIF $(\times 10.000$ magnification $)$ showing a dramatic reduction in the number of Weibel-Palade bodies (arrowheads) in transformed HIMEC. Figure is representative of two experiments ( $>5$ grids analyzed with 30 individual cells/condition) 
to that of HIF, and, notably, the number of Weibel-Palade bodies was dramatically reduced (Figure 1C).

Immunoblot analysis showed a progressive loss and eventual disappearance of CD31 and VE-cadherin with a parallel gain in vimentin and $\mathrm{N}$-cadherin expression in HIMEC exposed to single or combined cytokines (Figure $2 \mathrm{~A})$. As before, $\alpha$-SMA was detected only if TGF- $\beta 1$ was present, especially in combination with TNF- $\alpha$ or IL-1 $\beta$. qRTPCR corroborated these results by showing upregulated FSP-1 mRNA and downregulated VWF mRNA in transformed compared with untreated HIMEC (Figure 2B).

Staining for ganglioside 3G5, proteoglycan NG2, the high-molecular-weight myeloma-associated antigen $(\mathrm{HMW}-\mathrm{MAA})^{11,39}$ and desmin ${ }^{3}$ was negative in untreated and transformed HIMEC excluding the presence of pericyte or smooth muscle cell markers (not shown).

\section{Persistence of HIMEC Transformation}

We investigated whether phenotypic changes persisted on removal of the inducing agents. Once transformed (day 6), cultures were kept under endothelial cell-supporting conditions in the absence of any exogenous agents, and then re-examined by immunoblotting and qRT-PCR. After 10 days CD31, VE-cadherin and VWF were downregulated, whereas $\mathrm{N}$-cadherin and vimentin were still present (Figure $2 \mathrm{C}$ and $2 \mathrm{D}$ ), indicating a permanent change in cell phenotype. We systematically compared HIMEC from involved and noninvolved IBD tissue to HIMEC from normal control tissue for all of the above morphological and phenotypic parameters, but no quantitative or qualitative difference in the transformation process was observed.

\section{Acetylated LDL Uptake, Migration, and ECM Synthesis by Transformed HIMEC}

Uptake of acetylated LDL, a prototypical feature of endothelial cells, ${ }^{40}$ is also carried out by HIMEC. Transformed HIMEC displayed a markedly reduced capacity for LDL uptake, which was entirely absent in cells with a full spindle cell morphology (see Supplemental Figure S1 at http://ajp.amjpathol.org). Intestinal fibroblasts had no capacity to take up LDL. Reduced LDL uptake was particularly striking after prolonged HIMEC transformation (20 days).

Based on in vivo distribution and function, transformed HIMEC should show reduced mobility spontaneously or in response to inducers of endothelial cell migration like basic FGF and VEGF ${ }^{41}$ compared with mesenchymal cells. When migration of transformed HIMEC was tested and compared with that of untreated HIMEC, spontaneous and induced migratory capacity were significantly reduced and similar to that of HIF (see Supplemental Figure S2 at http://ajp. amjpathol.org). This change occurred with preservation of viability and proliferative activity.

Secretion of collagen I is the hallmark of mesenchymal cells and its production increases in various inflammatory conditions, including IBD. ${ }^{1,42,43}$ After transformation by combined TGF- $\beta 1$, TNF- $\alpha$, and IL- $1 \beta$ treatment, HIMEC acquired the de novo capacity of producing collagen I
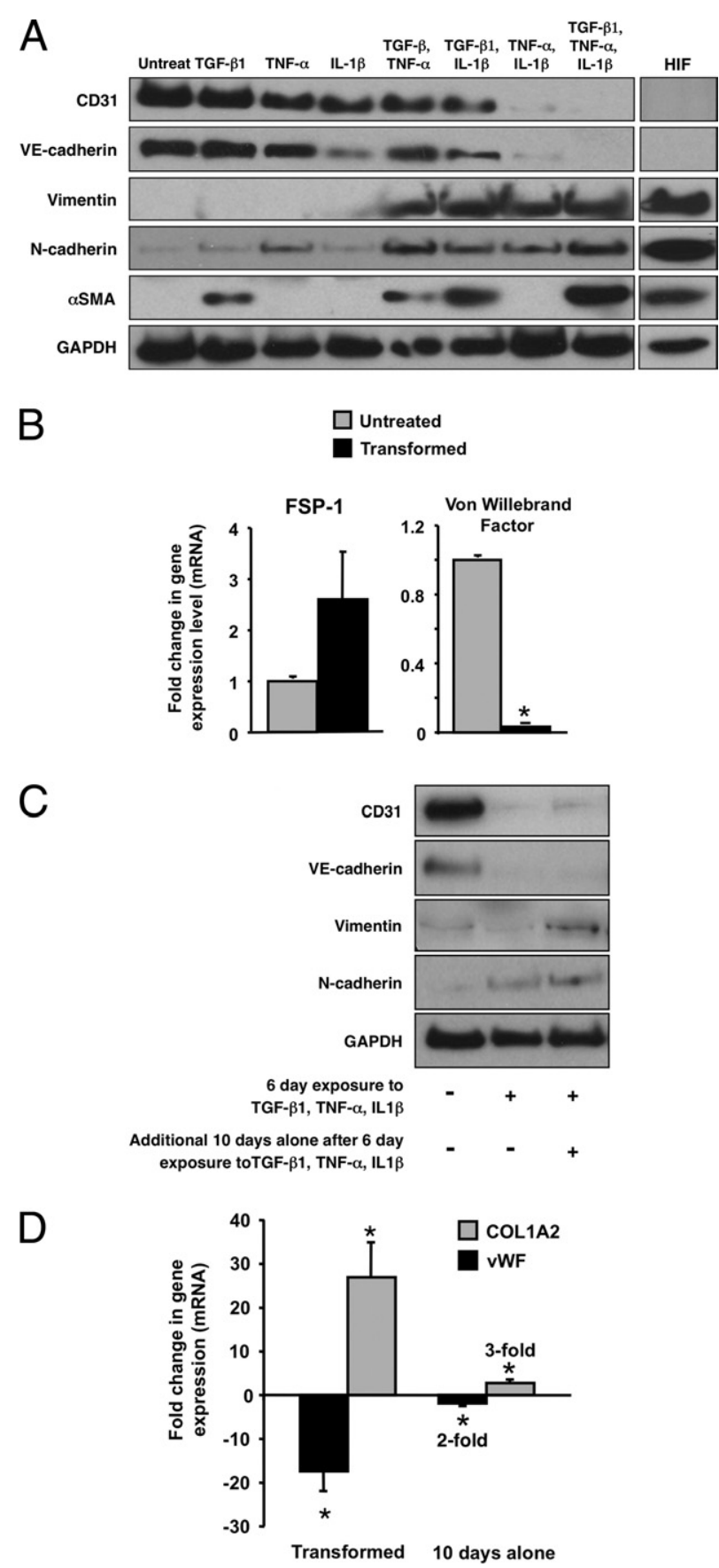

Figure 2. Changes occurring in HIMEC transformation. A: Changes in marker expression in transformed HIMEC. Immunoblot of HIMEC extracted after 6 days of transformation shows a progressive loss of CD31 and VE-cadherin and parallel acquisition of vimentin and $\mathrm{N}$-cadherin on exposure to the various cytokine combinations. $\alpha$-SMA was detected only when TGF- $\beta 1$ was present. Figure is representative of seven to nine experiments. B: Quantitative RT-PCR of mRNA marker expression in transformed HIMEC. qRT-PCR of total mRNA from HIMEC treated with or without combined TGF- $\beta 1$, TNF- $\alpha$, and IL- $1 \beta$ for 6 days. Values are shown as fold change in expression level in the absence (gray bars) or presence of TGF- $\beta 1$, TNF $\alpha$ and IL- $1 \beta$ (black bars). $n=8 ;{ }^{*} P<0.05$. C: Persistence of HIMEC transformation. Immunoblot of HIMEC extracts treated as in $\mathbf{B}$, before and after transformation and culture in the absence of any exogenous stimuli. After an additional 10-day period without transformationinducing factors, CD31 and VE-cadherin were still downregulated, whereas N-cadherin and vimentin were still present. Figure is representative of six experiments. D: Persistence of HIMEC transformation. qRTPCR analysis of HIMEC treated as in $\mathbf{C}$. At the end of an additional 10-day period without transformation-inducing factors, vWF was still downregulated, whereas Col1a2 was still upregulated. $n=6 ;{ }^{*} P<0.05$. 
protein, as demonstrated by immunoblotting, immunofluorescence, and qRT-PCR (Figure $3 \mathrm{~A}-\mathrm{C}$ ). Because fibronectin levels are known to increase in intestinal fibrosis, ${ }^{2,44,45}$ its expression was assessed by immunoblotting in nontransformed HIMEC and compared with that of HIMEC exposed to the combination of TGF- $\beta 1$, TNF- $\alpha$ and IL-1 $\beta$ for 9 days. Densitometric analysis showed a significant $1.45 \pm 0.08(P<0.001 ; n=11)$ fold increase in the expression of fibronectin in the transformed compared with untransformed HIMEC. Tenascin C mRNA (Figure 3C), another ECM molecule the levels of which also increase in intestinal fibrosis, ${ }^{2,44,45}$ similarly increased in transformed HIMEC, whereas expression of nidogen 1 mRNA, a basement membrane component, was reduced (Figure $3 \mathrm{C}$ ). The de novo acquired ability to produce collagen I persisted on removal of the inducing factors for up to 10 days culture without transformationinducing factors (Figure 2D).

To determine whether any difference existed in the response of HIMEC from inflamed and noninflamed IBD tissue (CD and UC) or normal tissue, we compared the same functional parameters and could not detect any quantitative or qualitative difference.

\section{Global Gene Profile Changes Associated with EndoMT}

To assess regulatory changes accompanying HIMEC transformation, we performed microarray analysis comparing transformed to autologous untreated HIMEC. In HIMEC undergoing transition, >1.5-fold changes were detected in 1769 genes (884 down and 885 upregulated). Transformed HIMEC downregulated the expression level of genes typically expressed in endothelial cells, such as VWF, VE-cadherin, and CD31, and upregulated genes typical of mesenchymal cells, like FSP-1, $\mathrm{N}$-cadherin, ACTA2, and Thy-1. Expression of several genes encoding ECM proteins that increase in intestinal fibrosis was upregulated, including fibronectin, tenascin $\mathrm{C}$, and collagen I. In contrast, genes for ECM components typically expressed by endothelial cells or found in basement membranes, eg, collagen IV, collagen VIII, or entactin, were downregulated. The pattern and extent of expression was similar in control and IBD HIMEC. Sixty genes relevant to fibrosis or EndoMT are shown in Figure 4 (left panel). HIMEC incubated with supernatants of LPMC showed genomic patterns comparable to those induced by TGF- $\beta 1, \mathrm{TNF}-\alpha$, and $\mathrm{IL}-1 \beta$ (see http://www.ncbi.nlm.nih.gov/geo/query/acc.cgi?token= bhqhvqyoyygqazy\&acc=GSE15975).

To identify the main transcription factors involved in EndoMT, we applied the Analyze Networks algorithm in MetaCoreTM to the 60 genes regulated during HIMEC transformation. Sp1 resulted as the transcription factor regulating the largest number of EndoMT-related genes (33 of 60 genes), including SMAD3 and NF- $\kappa$ B (Figure 4, right panel). Both $\mathrm{c}$-jun and $\mathrm{c}$-fos were also prominent, regulating 19 of 60 and 18 of 60 genes, respectively. These transcription factors regulate networks enriched in genes involved in organ development, inflammation, and

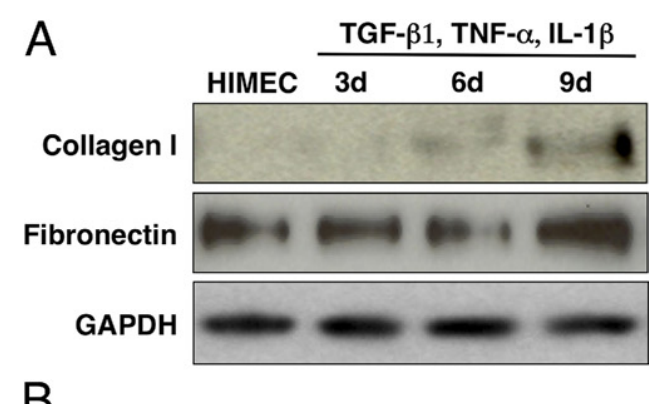

B
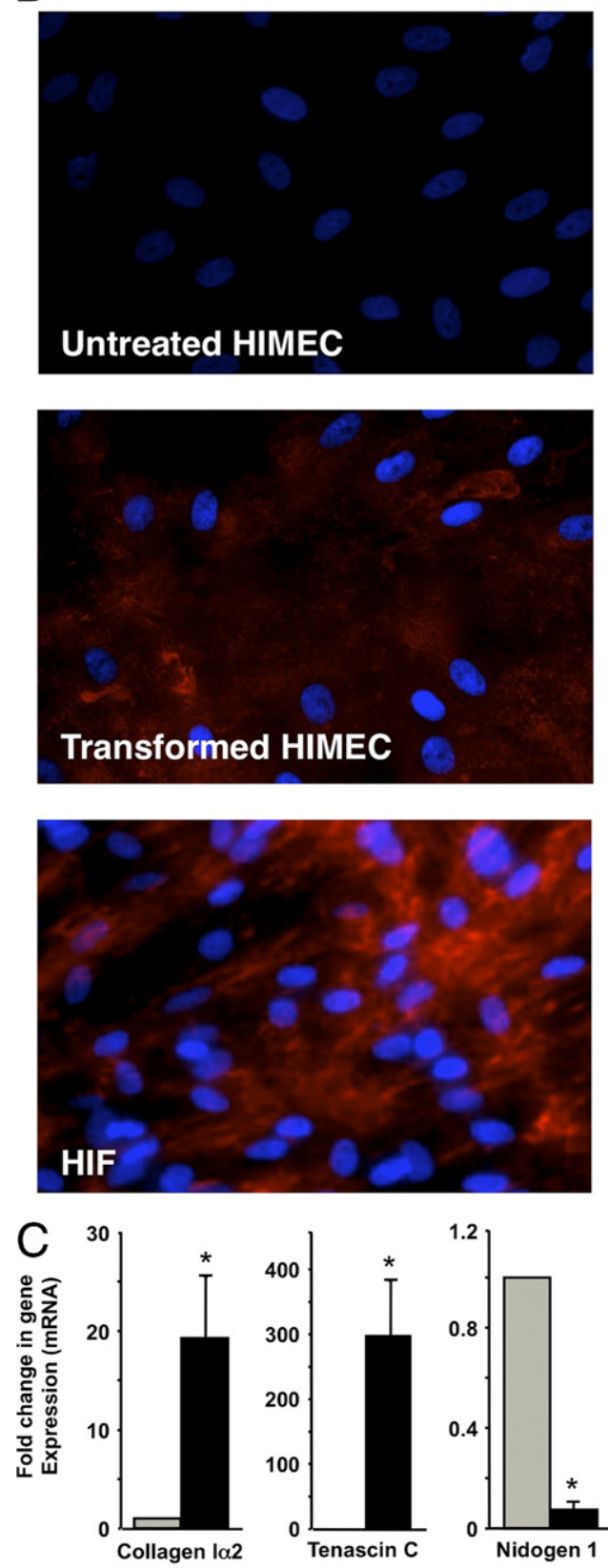

Figure 3. ECM production by transformed HIMEC. A: Immunoblot showing de novo capacity of producing collagen I protein and increased fibronectin production by transformed HIMEC. Figure is representative of two to five experiments. B: Immunofluorescence image of HIMEC shown in A demonstrating de novo production of collagen I by transformed HIMEC, and constitutive production of collagen I by HIF. Figure is representative of eight experiments. C: qRT-PCR analysis showing upregulation of mRNA for collagen I $\alpha 2$ and tenascin $\mathrm{C}$, and downregulation of nidogen mRNA in transformed HIMEC. Values shown as fold change in expression level in the absence (gray bars) and presence of TGF- $\beta 1$, TNF $\alpha$, and IL- $1 \beta$ (black bars). $n=8 ;{ }^{*} P<0.05$. 


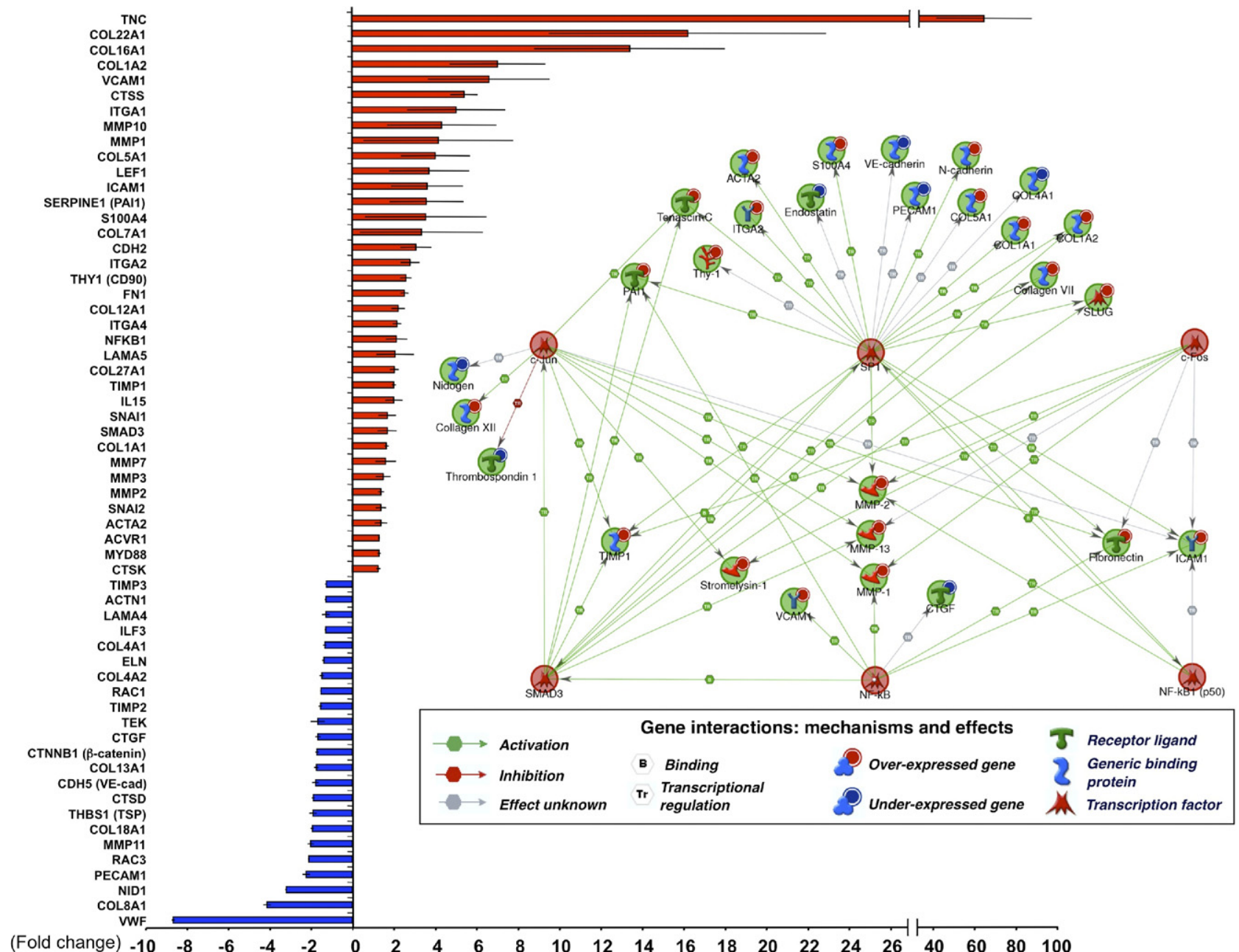

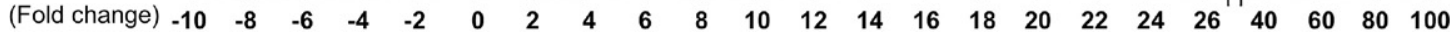

Figure 4. Microarray analysis of transformed HIMEC (left). Total RNA from HIMEC incubated with or without TGF- $\beta 1$, TNF $\alpha$, and IL-1 $\beta$ was hybridized to Illumina GeneChips. Expression of 60 genes involved in fibrogenesis or cellular transformation in transformed compared with untreated HIMEC is shown. Values shown as fold change in expression level of upregulated (red bars) and downregulated (blue bars) genes. Figure is representative of four separate HIMEC preparations. Network analysis for transcription factors involved in EndoMT (right). Gene regulatory network generated using MetaCore analytical suite of the microarray analyses showing that endothelial and mesenchymal genes that are transcriptionally regulated primarily through Sp1, c-jun, c-fos, Smad3, and NF- $\mathrm{B}$. Red background circles represent transcription factors, whereas green background circles represent targeted genes.

tissue remodeling. In particular, Sp1 was dominant in the gene network investigated, which included selective ECM and mesenchymal cell genes (such as collagen I and $\mathrm{V}$, S100A4, Thy-1 and ACTA2) that increased during EndoMT, and endothelial cell and basement membrane genes (VEcadherin, CD31, collagen IV) that were modulated during HIMEC transformation (Figure 4, right panel).

\section{Evidence of EndoMT in Human Mucosa in Situ and ex Vivo Studies}

We next sought evidence for intestinal EndoMT directly in human tissue. First, using colonic CD and UC tissues with comparable degrees of active inflammation and histologically normal non-IBD colon as control, we consistently detected discrete areas of co-localization of $\alpha$-SMA with $\checkmark W F$ in microvessels scattered throughout CD and UC mucosa (Figure 5). Of note, this was observed only in areas where the mucosal microvasculature was in close association with inflammatory infiltrates (Figure 6A). Sec- ond, we tested whether native inflammatory mediators present in IBD mucosa could reproduce the EndoMT observed in vitro. The morphological changes induced by recombinant cytokines (Figure $1 \mathrm{~A}$ ) were fully replicated by exposure to supernatants of ex vivo activated LPMC (Figure 6B) as well as the downregulation of endothelial and upregulation of mesenchymal cell markers (Figure 6C).

TGF- $\beta 1, \mathrm{IL}-1 \beta$, and TNF- $\alpha$ are abundant in activated LPMC supernatants. ${ }^{46}$ To determine which of these factors has the greatest capacity to induce EndoMT, we neutralized their biological activity individually and in combination. Blocking TGF- $\beta 1$ or TNF- $\alpha$ alone failed to restore the endothelial morphology of transformed HIMEC. In contrast, adding IL-1RA alone or in combination with anti-TGF- $\beta 1$ or anti-TNF- $\alpha$ preserved HIMEC original morphology (Figure 6B). Of note, LPMC supernatants contained substantial amounts of both IL- $1 \alpha$ and IL-1 $\beta(728 \pm 196$ and $855 \pm 150 \mathrm{pg} / \mathrm{mL}$, respectively; $n=13)$. Although blockade of TGF- $\beta 1$ did not alter the gene expression levels of VWF and Col1A2, blocking 


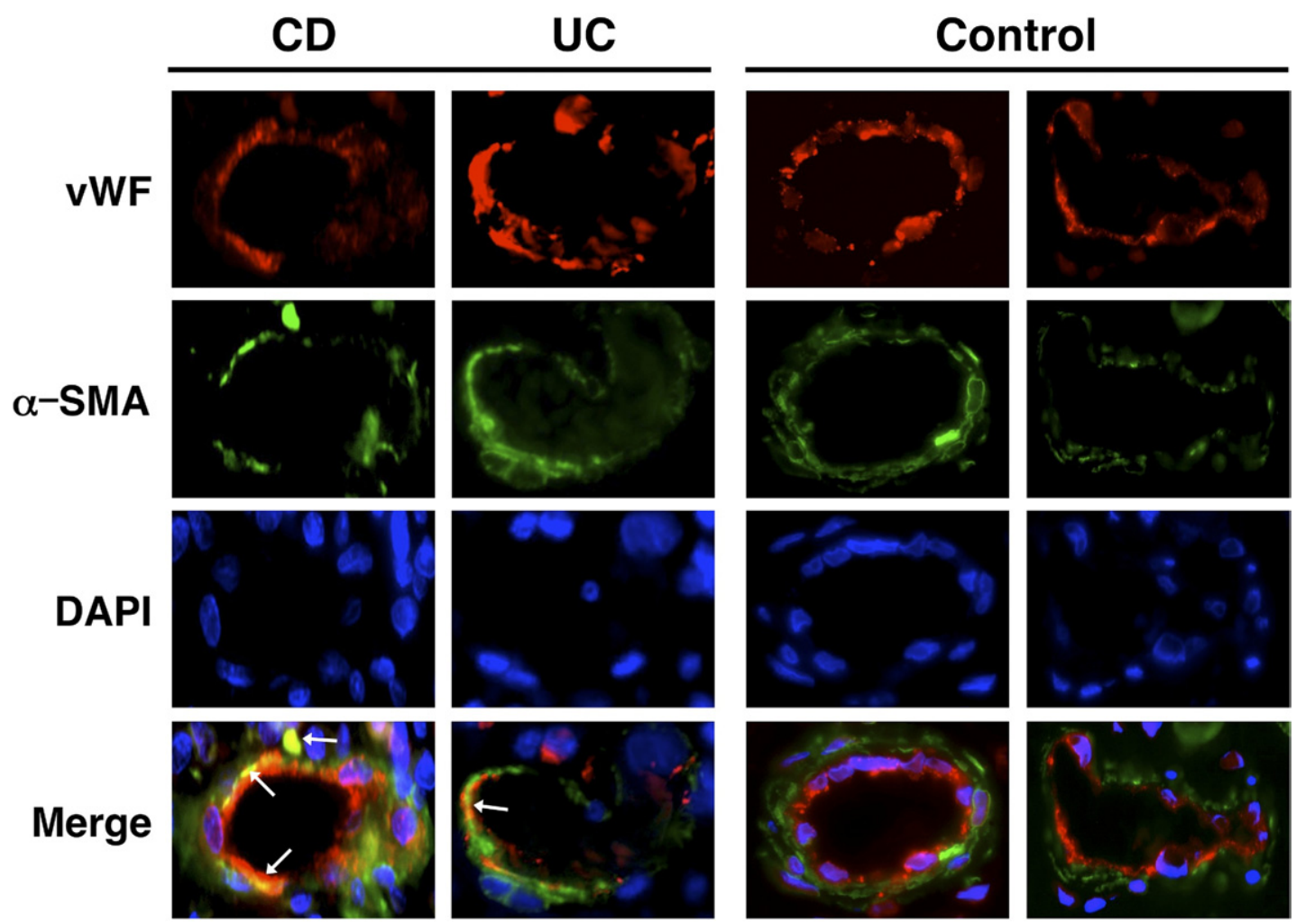

Figure 5. In situ evidence for EndoMT. Immunofluorescence images of human colonic mucosa stained with vWF (red) and $\alpha$-SMA (green). Co-localization (arrows) of these mesenchymal and endothelial proteins was detected (merged yellow color) in discrete microvessels scattered throughout the mucosa of CD and UC, but not control specimens. Nuclei were counterstained with DAPI (blue). Figure is representative of 10 CD, three UC, and three control tissues.

TNF- $\alpha$ partially restored $v W F$ gene expression in transformed HIMEC. Importantly, adding IL-1RA alone or together with TGF- $\beta 1$ and TNF- $\alpha$ almost completely restored the gene expression of $\mathrm{VWF}$ and to a lesser degree of Col1A2 (Figure 6D). No differences were noted between control or IBD LPMC supernatants (not shown).

\section{Evidence of EndoMT in Vivo within Animal Studies}

We sought direct evidence for intestinal EndoMT in vivo using an intestinal inflammation-induced fibrosis animal model. Because endothelial cells lose typical endothelial markers during the transformation process, they can no longer be identified in vivo. Therefore, adopting the murine model of TNBS colitis-induced fibrosis, ${ }^{38}$ we used endothelial reporter mice in which GFP is expressed under the control of the endothelial cell-specific promoter Tie2. Cells of endothelial origin are marked by GFP expression $^{47,48}$ and even after transformation can still be recognized by the co-expression of mesenchymal markers and GFP.

After 8 weekly intrarectal injections of TNBS ${ }^{38}$ inflammatory infiltrates accompanied by substantial thickening of the muscularis mucosa, submucosa and muscularis propria as well as abundant collagen deposition were observed; none of these changes were seen in mice receiving PBS or ethanol (Figure 7A). GFP expression in the control animals (PBS or ethanol) was restricted to endothelial cells lining vessels of the mucosa and submucosa. In the TNBS-induced colonic fibrosis, however, GFP-expressing cells were found outside of the vessels and within the fibrotic areas (Figure 7A). When examined by confocal microscopy some of the GFP-expressing cells lining microvessels co-expressed $\alpha$-SMA, indicating acquisition of a typical mesenchymal cell marker (Figure 7B), and these double expressing cells were found in all tissue layers (Figure 7C). This occurred exclusively in TNBS-treated animals exhibiting both inflammation and fibrosis, whereas no GFP and $\alpha$-SMA-coexpressing cells could be found in PBS or ethanol enema-treated animals.

\section{Discussion}

Cell transformation occurs during embryologic development as well as in cancer and fibrosis. EMT and EndoMT selectively contribute to fibrosis in the skin, lung, kidney, liver, heart, and lung, where inflammation appears to be the central driving force. ${ }^{18-21,49}$ Considering the proximity of inflammatory infiltrates to the microvasculature in vivo, EndoMT could also occur in IBD. On exposure to recombinant cytokines or ex vivo inflammatory mediators, human mucosal endothelial cells underwent morphological, phenotypic, and functional changes consistent with EndoMT. Changes occurred regardless of whether HIMEC derived from normal and involved or uninvolved IBD mucosa. Of note, pre-exposure to inflammation in 
A
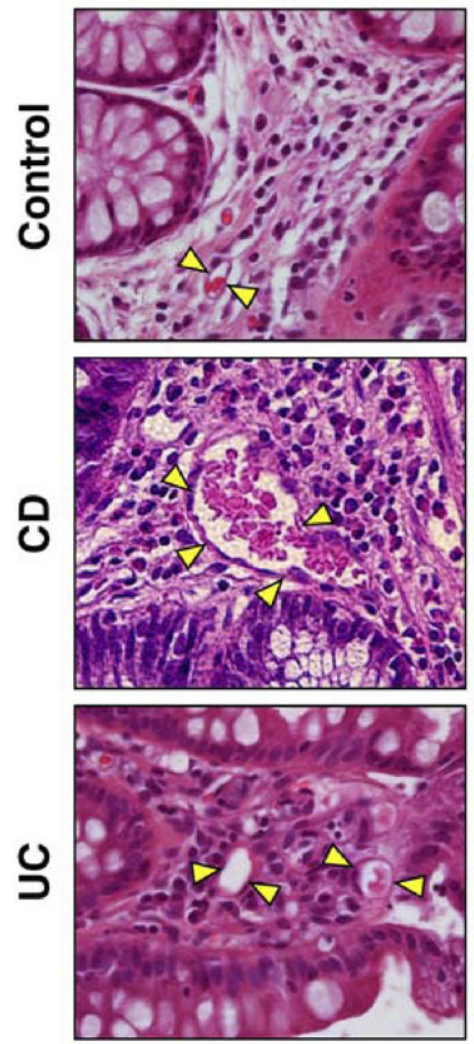

C

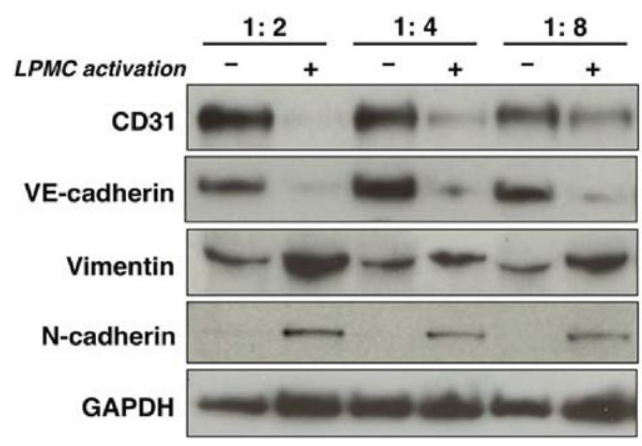

Trichrome
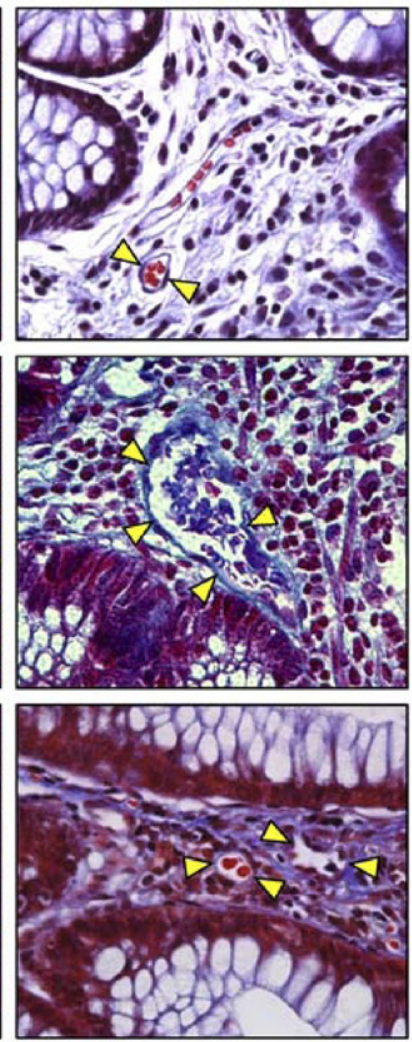

B
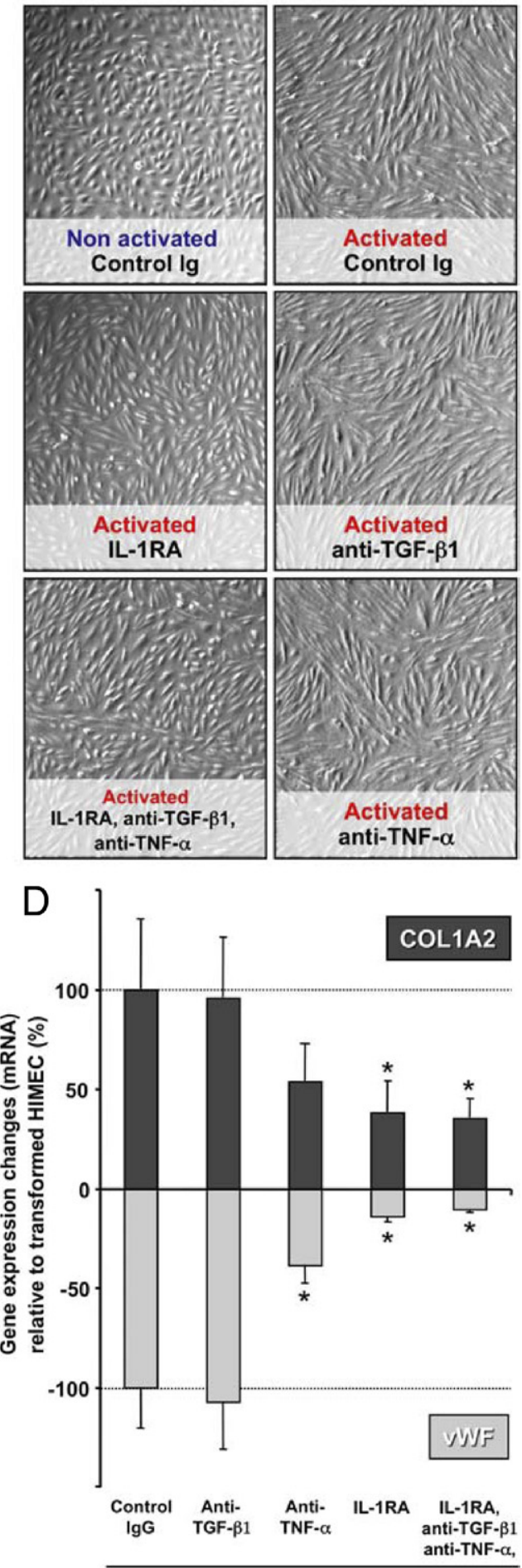

Activated LPMC supernatants

Figure 6. Changes in morphology and gene expression in transformed HIMECs. A: Association of inflammatory infiltrates and intestinal microvessels (arrowheads). H\&E and Masson trichrome staining of normal control colonic mucosa and colonic mucosa involved by active CD or UC. Figure is representative of four control, eight CD, and three UC tissues. B: Morphological changes in transformed HIMEC induced by LPMC supernatants. HIMEC were treated with supernatants of nonactivated or activated LPMC for 6 days at 1:2, $1: 4$, and 1:8 dilutions. Cytokines in the supernatants were neutralized by IL-1RA, anti-TGF- $\beta 1$, or anti-TNF- $\alpha$, alone or in combination using isotype IgG as control. Figure is representative of 10 experiments. C: Changes in marker expression in transformed HIMEC induced by LPMC supernatants. Immunoblot of HIMEC treated as in B with supernatants of nonactivated ( - ) or activated (+) LPMC for 6 days. Transformed HIMEC incubated with activated supernatants showed a loss of CD31 and VE-cadherin and acquisition of vimentin and N-cadherin. Figure is representative of six experiments. D: Changes in gene expression in transformed HIMEC after cytokine neutralization. HIMEC exposed to supernatants of activated LPMC (1:4) for 6 days or cytokines were treated with IL-1RA, anti-TGF- $\beta 1$, or anti-TNF- $\alpha$, alone or in combination, using isotype IgG as control. qRT-PCR showed partial restoration of vWF mRNA after TNF- $\alpha$ neutralization, a partial restoration of COL1A2, and an almost complete restoration of vWF mRNA by blockade of IL- $1 \beta$ alone or of all three cytokines. $n=6 ; P<0.05$. 
A

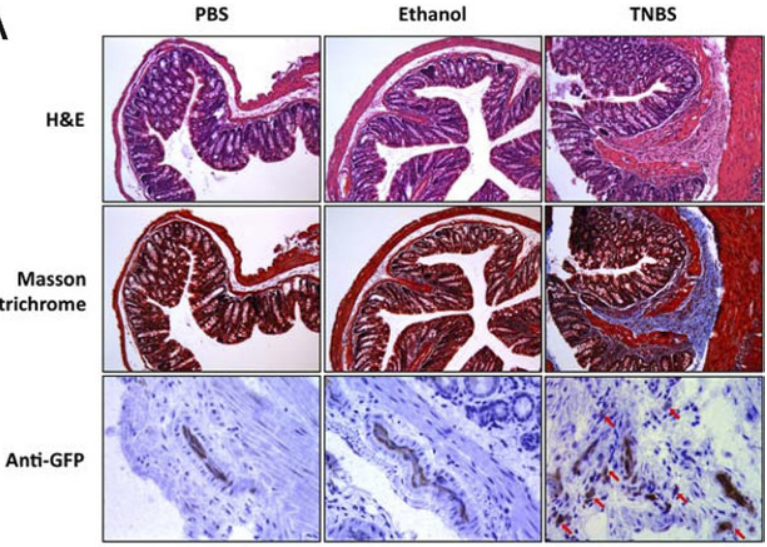

B
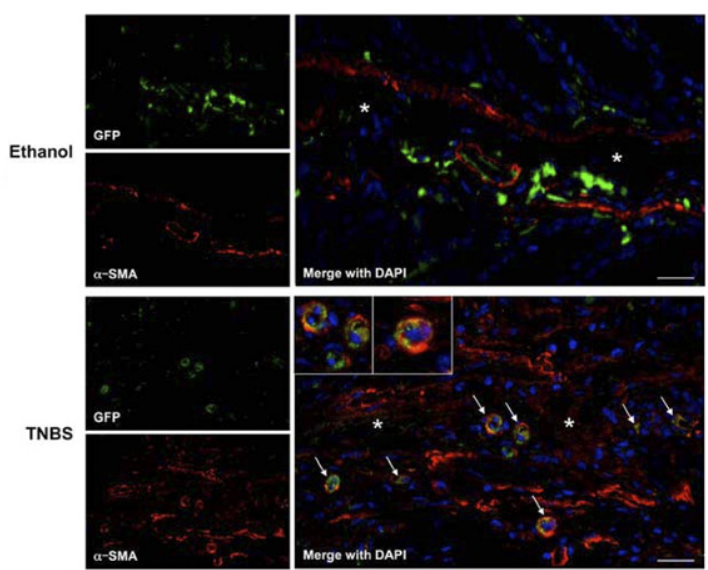

C
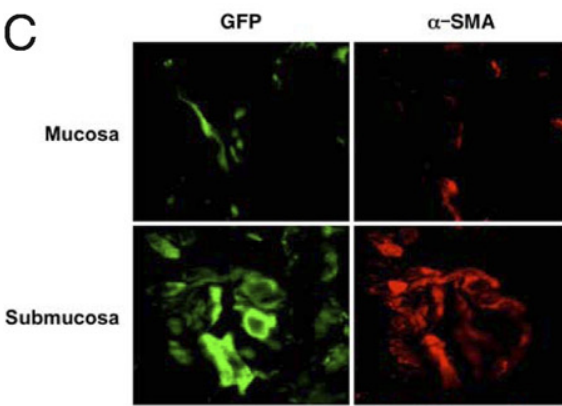

Merge with DAPI
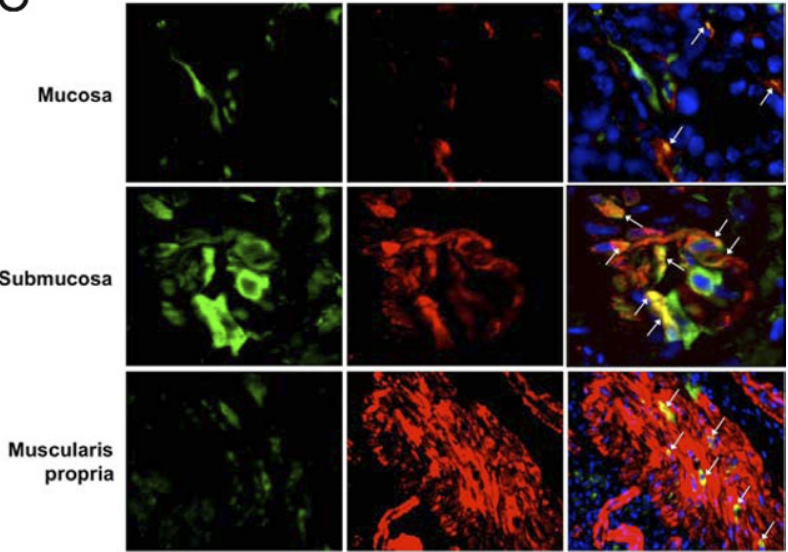

Figure 7. In vivo EndoMT in the murine model of trinitrobenzene sulfonic acid (TNBS)-induced fibrosis. A: Murine model of TNBS fibrosis using Tie2-GFP endothelial reporter mice expressing GFP under the control of the Tie 2 promoter. Mice were administered intrarectal injections of TNBS, ethanol, or PBS over 8 weeks, after which the colon was stained with H\&E $(\times 100$ magnification), Masson trichrome $(\times 100)$, or anti-GFP antibody $(\times 400)$. Inflammatory infiltrates and massive thickening of the muscularis mucosae and muscularis propria are noted. Numerous GFP-positive cells are found outside of vessels and deep within fibrotic areas of the submucosa (arrows). Picture representative of six experiments in each group. B: Immunofluorescence of colon submucosa (asterisks) of the same mice stained with anti- $\alpha$-SMA (red) or anti-GFP antibody (green) and nuclei counterstained with DAPI (blue). Doublepositive (merge) cells appear in yellow. Cells co-expressing $\alpha$-SMA and GFP were detected inside the vessels as well as deep in the fibrotic area (arrows and inset). Pictures are representative of five experiments. C: Double positive cells (arrows) found in all tissue layers of the intestine. Original magnification: $\times 200$ for submucosa in $\mathbf{B}$ (right panels) and muscularis propria in $\mathbf{C}$, and $\times 600$ for mucosa and submucosa in $\mathbf{C}$. vivo, as occurs in active IBD, was not a requisite for endothelial transdifferentiation in vitro, suggesting that EndoMT is readily inducible in the gut without pre-conditioning. Thus, the gut mucosal microvasculature seems intrinsically susceptible to transformation, a notion corroborated by the induction of EndoMT in vivo in a murine model of colonic fibrosis.

IL-1 $\beta$ was sufficient to induce all events required for HIMEC EndoMT with the notable exception of de novo acquisition of $\alpha$-SMA, which was strictly dependent on TGF- $\beta 1$. Others have reported that TGF- $\beta 1$ alone can induce EndoMT in the lung, heart and kidney. ${ }^{50-52} \mathrm{~A}$ reason for this organ-dependent difference may be the uniquely high content of TGF- $\beta 1$ in the intestine ${ }^{53}$; otherwise, EndoMT would occur under physiological conditions. Other differences may depend on the macrovasculature versus the microvasculature. TGF- $\beta 1$ induces EndoMT in lung and heart macrovascular endothelial cells, but is dispensable for EndoMT of dermal microvascular endothelial cells. ${ }^{21,51}$ Another level of conditioning may be needed for EndoMT in the gut, a conclusion supported by the observation that LPMC supernatants effectively induced transformation. The neutralization experiments clearly point to IL-1 as the dominant factor responsible for EndoMT. In fact, because LPMC supernatants reflect the in vivo situation, contain abundant quantities of both $\mathrm{IL}-1 \alpha$ and $\mathrm{IL}-1 \beta$, and their biological activity is similarly blocked by IL1RA, these cytokines appear to be the main drivers of EndoMT in IBD. This conclusion is supported by the failure of bone morphogenic protein 7 (BMP-7), an agent that prevents EMT by inhibiting TGF- $\beta$ activity, ${ }^{18}$ to block or reverse HIMEC transdifferentiation in vitro (not shown). It should also be noted that LPMC supernatants contain a vast array of soluble mediators, and it cannot be entirely excluded that other molecules may also contribute, to some degree, to the phenomenon of EndoMT.

EndoMT appeared completed at the end of 6 days of cytokine exposure because, by then, HIMEC had lost the endothelial markers CD31, VWF, and VE-cadherin and had acquired mesenchymal cell markers (vimentin, $\mathrm{N}$ cadherin, $\alpha$-SMA, and FSP-1) in addition to displaying mesenchymal cell morphology. Prolonging transforming conditions did not result in additional changes, suggesting the creation of a stable mesenchymal phenotype. Translated to the in vivo situation, these findings imply that the transdifferentiated cells remain and expand the pool of mucosal mesenchymal cells even after inflammation has subsided. This is supported by models of experimental IBD, in which fibrogenic genes remain upregulated after inflammation-associated genes have returned to basal levels. ${ }^{54}$ A pericyte and smooth muscle cell contribution to the mesenchymal cell pool was excluded by the lack of the pericyte markers NG-2, 3G5, and HMW-MAA, and of desmin, which is abundant in smooth muscle cells. ${ }^{3,11,39}$ This validated the endothelial nature of the transformed cells, which exhibited a phenotype indistinguishable from that of HIF., ${ }^{1,3}$ Importantly, EndoMT resulted in functional differentiation as measured by migratory capacity, LDL uptake and ECM production. 
Compared with endothelial cells transformed HIMEC should display a limited migratory capacity as observed in resident mesenchymal cells. This was the case, conceivably facilitating retention of the transformed cells, expand the mesenchymal cell pool, and thus contributing to fibrosis. The loss of endocytic activity, shown by the inability of transformed cells to uptake LDL, was remarkable considering that all endothelial cells display strong nonspecific (pinocytosis) and receptor-mediated LDL endocytosis. ${ }^{40}$ During transformation HIMEC increased fibronectin production and acquired the de novo ability to produce collagen I, a feature absent in nontransformed cells. The enhanced production of ECM combined with loss of migratory capacity could render transformed HIMEC just as effective as native mesenchymal cells in promoting wound healing and fibrosis. . $^{3,55}$ In this regard, the concomitant reduction in VWF and increase of Col1A2 gene expression, and the persistence of these changes after cytokine removal suggest a permanent transformation allowing HIMEC to exert long-lasting pro-fibrogenic effects.

Complex and global changes underlie EndoMT ${ }^{56,57}$ Genomic analysis confirmed that transformed HIMEC enhanced the expression of genes encoding for collagen I, fibronectin, and tenascin $C^{1,2,42-45}$ concurrently expressed lower levels of genes encoding for ECM necessary for endothelial basement membrane assembly, like collagen IV, collagen VIII, or entactin, and secreted high amounts of bioactive MMP2 (not shown). These findings suggest that during transformation mucosal endothelial cells may enzymatically degrade the basement membrane and downregulate production of basement membrane proteins to allow the transformed cell to invade the surrounding interstitium. We did not specifically investigate whether EndoMT affect the number and diameter of microvessels in the inflamed tissue. However, we have previously reported that in IBD mucosal microvessels display an increased number of vessels per field, mean vessel area, percent section area, and large vessel diameters. ${ }^{41}$ It is also possible that EndoMT creates leaky vessels that facilitate increased leukocyte extravasation. In fact, we and other groups have described various abnormalities of mucosal microvessel function in human and experimental IBD. ${ }^{58,59}$ All these effects may be enhanced by the increased angiogenesis of IBD tissues, ${ }^{41}$ by providing a rich substrate for EndoMT and generation of more fibroblasts. As fibroblasts are a major source of pro-angiogenic factors, their increase could further promote angiogenesis, and conceivably create a self-perpetuating loop of angiogenesis-dependent EndoMT amplified by fibroblast-derived pro-angiogenic factors, a scenario proposed in carcinoma-associated fibrosis. ${ }^{60}$

To gain insight regarding the genes controlling intestinal EndoMT, we performed an investigation using microarray genomics transcription factors associated with transformation. Sp1, c-jun, and c-fos were the dominant transcription factors detected in association with the process of EndoMT, with a lesser role for NF- $\kappa$ B. Although the identification of $\mathrm{c}$-jun and c-fos was not surprising, the prominent nature of Sp1 was unexpected. Sp1 is thought of as an activator of housekeeping and intermediary me- tabolism gene, but recently its involvement in proliferation, tumorigenesis, and collagen metabolism has been demonstrated. ${ }^{61,62}$ It should be noted that the results of the bioinformatics analysis do not prove that $\mathrm{Sp} 1$ or the other factors are the main transcriptional regulators of EndoMT. Nevertheless, they provide specific targets for future experiments where their blockade (by RNA silencing, for example) may prevent or reverse the phenomenon of HIMEC transformation.

To translate the above findings to the in vivo situation, we sought evidence of EndoMT in human and murine intestine. Co-expression of endothelial and mesenchymal markers, compatible with ongoing EndoMT, was found in microvascular cells of both CD and UC mucosa, but only in actively inflamed tissue. This suggests first that the underlying disease process is not the primary determinant of EndoMT but, rather, the degree and duration of inflammation; second, once endothelial markers have disappeared and mesenchymal markers are expressed, the endothelial phenotype is permanently lost and immunohistochemical detection of transformed cells in situ is no longer possible in human tissues. Additional evidence of EndoMT in vivo was obtained using a model of inflammation-induced fibrogenesis in endothelial cell reporter mice, where the fate of GFP-flagged endothelial cells can be followed in vivo even after full transformation. 18,19,52 The finding of GFP-expressing cells outside of the vessels and deep within fibrotic areas of all layers of the inflamed colon confirms the notion that EndoMT occurs in the inflamed gut and contributes to fibrosis.

To what extent EndoMT and, for the same reason, EMT contributes to fibroblast accumulation and ECM deposition is currently a matter of controversy. ${ }^{63}$ This can be theoretically assessed in experimental animal models using tagged cells, but the results of these studies are far from conclusive because of considerable variation of the experimental conditions and the methods used to "quantify" transformed cells in "selected" tissue sections. ${ }^{63}$ Furthermore, this information cannot be translated to human tissues because specific markers are lost once the endothelial cells have fully transformed. The key point, however, is the unequivocal demonstration that the phenomenon of EndoMT is real, as we showed in both human and murine tissues exposed to similar inflammatory conditions.

In summary, these studies provide strong evidence that EndoMT readily occurs in the intestine exposed to inflammatory stress, as seen in human IBD mucosa and experimental colitis, and contributes to local fibrogenesis. Targeting EndoMT has been proposed as a novel therapeutic strategy in cancer and various other disease states. ${ }^{57}$ Considering the serious clinical implications of fibrosis in IBD, preventing or blocking EndoMT may be a novel and useful approach to eliminate or reduce inflammation-induced fibrosis and stricture formation.

\section{Acknowledgments}

The authors acknowledge the support of the Departments of Colorectal Surgery and Pathology of the Cleve- 
land Clinic Foundation. Tissue samples were provided by the Human Tissue Procurement Facility of the Cleveland Clinic Foundation, Cleveland, Ohio.

\section{References}

1. Rieder F, Fiocchi C: Intestinal fibrosis in IBD—a dynamic, multifactorial process. Nat Rev Gastroenterol Hepatol 2009, 6:228-235

2. Burke JP, Muslow JJ, O'Keane C, Docherty NG, Watson RWG, O'Connell PR: Fibrogenesis in Crohn's disease. Am J Gastroenterol 2007, 102:439-448

3. Pucilowska JB, Williams KL, Lund PK: Fibrogenesis. IV. Fibrosis and inflammatory bowel disease: cellular mediators and animal models. Am J Physiol Gastrointest Liver Physiol 2000, 279:G653-G659

4. Lund PK, Zuniga CC: Intestinal fibrosis in human and experimental inflammatory bowel disease. Curr Opin Gastroenterol 2001, 17:318323

5. Lawrance IC, Maxwell L, Doe W: Altered response of intestinal mucosal fibroblasts to profibrogenic cytokines in inflammatory bowel disease. Inflamm Bowel Dis 2001, 7:226-236

6. Brittan M, Chance V, Elia G, Poulsom R, Alison MR, MacDonald TT, Wright NA: A regenerative role for bone marrow following experimental colitis: contribution to neovasculogenesis and myofibroblasts. Gastroenterology 2005, 128:1984-1995

7. Leeb SN, Vogl D, Gunckel M, Kiessling S, Falk W, Göke M, Schölmerich J, Gelbmann CM, Rogler G: Reduced migration of fibroblasts in inflammatory bowel disease: role of inflammatory mediators and focal adhesion kinase. Gastroenterology 2003, 125:1341-1354

8. Leite AZ, delaMotte C, Strong SA, Fiocchi C: Isolation and functional characterization of human intestinal mucosal stellate cells. Gastroenterology 2002, 122:A-111 (Abstract)

9. Kalluri R, Neilson EG: Epithelial-mesenchymal transition and its implications for fibrosis. J Clin Invest 2003, 112:1776-1784

10. Bellini A, Mattoli S: The role of the fibrocyte, a bone marrow-derived mesenchymal progenitor, in reactive and reparative fibroses. Lab Invest 2007, 87:858-870

11. Gerhardt H, Betsholtz C: Endothelial-pericyte interactions in angiogenesis. Cell Tissue Res 2003, 314:15-23

12. Kalluri R, Weinberg RA: The basics of epithelial-mesenchymal transition. J Clin Invest 2009, 119:1420-1428

13. Bates RC, Mercurio AM: Tumor necrosis factor-alpha stimulates the epithelial-to-mesenchymal transition of human colonic organoids. Mo Biol Cell 2003, 14:1790-1800

14. Bataille F, Rohrmeier C, Bates R, Weber A, Rieder F, Brenmoehl J, Strauch U, Farkas S, Fürst A, Hofstädter F, Schölmerich J, Herfarth H, Rogler G: Evidence for a role of epithelial mesenchymal transition during pathogenesis of fistulae in Crohn's disease. Inflamm Bowel Dis 2008, 14:1514-1527

15. Flier SN, Tanjore H, Kokkotou EG, Sugimoto H, Zeisberg M, Kalluri R: Identification of epithelial to mesenchymal transition as a novel source of fibroblasts in intestinal fibrosis. J Biol Chem 2010, 285: 20202-20212

16. Romero LI, Zhang DN, Herron GS, Karasek MA: Interleukin-1 induces major phenotypic changes in human skin microvascular endothelial cells. J Cell Physiol 1997, 173:84-92

17. Frid MG, Kale VA, Stenmark KR: Mature vascular endothelium can give rise to smooth muscle cells via endothelial-mesenchymal transdifferentiation: in vitro analysis. Circ Res 2002, 90:1189-1196

18. Zeisberg M, Hanai J, Sugimoto H, Mammoto T, Charytan D, Strutz F, Kalluri R: BMP-7 counteracts TGF-beta1-induced epithelial-to-mesenchymal transition and reverses chronic renal injury. Nat Med 2003, 9:964-968

19. Zeisberg EM, Tarnavski O, Zeisberg M, Dorfman AL, McMullen JR, Gustafsson E, Chandraker A, Yuan X, Pu WT, Roberts AB, Neilson EG, Sayegh MH, Izumo S, Kalluri R: Endothelial-to-mesenchymal transition contributes to cardiac fibrosis. Nat Med 2007, 13:952-961

20. Hashimoto N, Phan SH, Imaizumi K, Matsuo M, Nakashima H, Kawabe T, Shimokata K, Hasegawa Y: Endothelial-mesenchymal transition in bleomycin-induced pulmonary fibrosis. Am J Respir Cell Mol Biol 2009, 43:161-172

21. Chaudhuri V, Zhou L, Karasek M: Inflammatory cytokines induce the transformation of human dermal microvascular endothelial cells into myofibroblasts: a potential role in skin fibrogenesis. J Cutan Pathol 2007, 34:146-153

22. Binion DG, West GA, Ina K, Ziats NP, Emancipator SN, Fiocchi C: Enhanced leukocyte binding by intestinal microvascular endothelial cells in inflammatory bowel disease. Gastroenterology 1997, 112: 1895-1907

23. Fiocchi C, Battisto JR, Farmer RG: Gut mucosal lymphocytes in inflammatory bowel disease. Isolation and preliminary functional characterization, Dig Dis Sci 1979, 24:705-717

24. Strong SA, Pizarro TT, Klein JS, Cominelli F, Fiocchi C: Proinflammatory cytokines differentially modulate their own expression in human intestinal mucosal mesenchymal cells. Gastroenterology 1998, 114: $1244-1256$

25. Musso A, Condon TP, West GA, delaMotte C, Strong SA, Levine AD, Bennett CF, Fiocchi C: Regulation of ICAM-1-mediated fibroblast-Tcell reciprocal interaction: implications for modulation of gut inflammation. Gastroenterology 1999, 117:546-556

26. Vogel JD, West GA, Sturm A, Danese S, delaMotte C, Phillips MH, Strong SA, Willis J, Fiocchi C: CD40-mediated immune-nonimmune cell interactions induce mucosal fibroblast chemokines causing T-cell transmigration. Gastroenterology 2004, 126:63-80

27. Ina K, Itoh J, Fukushima K, Kusugami K, Yamaguchi T, Kyokane $\mathrm{K}$, Imada A, Binion DG, Musso A, West GA, Dobrea GM, McCormick TS, Lapetina EG, Levine AD, Ottaway CA, Fiocchi C: Resistance of Crohn's disease T-cells to multiple apoptotic stimuli is associated with a Bcl-2/Bax mucosal imbalance. J Immunol 1999, 163:1081-1090

28. Saada JI, Pinchuk IV, Barrera CA, Adegboyega PA, Suarez G, Mifflin RC, DiMari JF, Reyes VE, Powell DW: Subepithelial myofibroblasts are novel nonprofessional APCs in the human colonic mucosa. J Immunol 2006, 177:5968-5979

29. DiSabatino A, Pender SLF, Jackson CL, Prothero JD, Gordon JN, Picariello L, Rovedatti L, Docena G, Monteleone G, Rampton DS, Tonelli F, Corazza GR, MacDonald TT: Functional modulation of Crohn's disease myofibroblasts by anti-tumor necrosis factor antibodies. Gastroenterology 2007, 133:137-149

30. Andoh A, Bamba S, Brittan M, Fujiyama Y, Wright NA: Role of intestinal subepithelial myofibroblasts in inflammation and regenerative response in the gut. Pharmacol Ther 2007, 114:94-106

31. Paunescu V, Bojin FM, Tatu CA, Gavriliuc OI, Rosca A, Gruia AT, Tanasie G, Bunu C, Crisnic D, Gherghiceanu M, Tatu FR, Tatu CS, Vermesan S: Tumor-associated fibroblasts and mesenchymal stem cells: more similarities than differences, J Cell Mol Med 2011, 15:635646

32. Pfaffl MW: A new mathematical model for relative quantification in real-time RT-PCR. Nucleic Acids Res 2001, 29:e45

33. Du P, Kibbe WA, Lin SM: lumi: a pipeline for processing Illumina microarray. Bioinformatics 2008, 24:1547-1548

34. Benjamini $Y$, Hochberg $Y$ : Controlling the false discovery rate: a practical and powerful approach to multiple testing, J R Stat Soc 1995, Ser. B57:289-300

35. Mason CW, Swaan PW, Weiner CP: Identification of interactive gene networks: a novel approach in gene array profiling of myometria events during guinea pig pregnancy. Am J Obstet Gynecol 2006, 194:1513-1523

36. Nikolsky $Y$, Ekins $S$, Nikolskaya $T$, Bugrim A: A novel method for generation of signature networks as biomarkers from complex high throughput data. Toxicol Lett 2005, 158:20-29

37. Chao A, Wang TH, Lee YS, Hong JH, Tsai CN, Chen CK, Tsai CS, Chao AS, Lai $\mathrm{CH}$ : Analysis of functional groups of differentially expressed genes in the peripheral blood of patients with cervical cancer undergoing concurrent chemoradiation treatment. Radiat Res 2008, 169:76-86

38. Lawrance IC, Wu F, Leite AZA, Willis J, West GA, Fiocchi C, Chakravarti S: A murine model of chronic inflammation-induced intestinal fibrosis down-regulated by antisense NF- $\kappa$ B. Gastroenterology 2003, 125:1750-1761

39. Helmbold P, Nayak RC, Marsch WC, Herman IM: Isolation and in vitro characterization of human dermal microvascular pericytes. Microvasc Res 2001, 61:160-165

40. Voyta JC, Via DP, Butterfield CE, Zetter BR: Identification and isolation of endothelial cells based on their increased uptake of acetylated-low density lipoprotein. J Cell Biol 1984, 99:2034-2040

41. Danese S, Sans M, delaMotte C, Graziani C, West G, Phillips MH, Pola R, Rutella S, Willis J, Gasbarrini A, Fiocchi C: Angiogenesis as a novel 
components of inflammatory bowel disease pathogenesis. Gastroenterology 2006, 130:2060-2073

42. Stallmach A, Schuppan D, Riese HH, Matthes H, Rieken EO: Increased collagen type III synthesis by fibroblasts isolated from strictures of patients with Crohn's disease. Gastroenterology 1992, 102: 1920-1929

43. Arihiro S, Ohtani H, Hiwatashi N, Torii A, Sorsa T, Nagura H: Vacular smooth muscle cells and pericytes express MMP-1. MMP-9, TIMP-1 and type I procollagen in inflammatory bowel disease, Histopathology 2001, 19:50-59

44. Riedl SE, Faissner A, Schlag P, VonHerbay A, Koretz K, Moller P: Altered content and distribution of tenascin in colitis, colon adenoma, and colorectal carcinoma. Gastroenterology 1992, 103:400-406

45. Brenmoehl J, Lang M, Hausmann M, Leeb SN, Falk W, Scholmerich J, Goke M, Rogler G: Evidence for a differential expression of fibronectin splice forms ED-A and ED-B in Crohn's disease (CD) mucosa. Int J Colorectal Dis 2007, 22:611-623

46. Youngman KR, Simon PL, West GA, Cominelli F, Rachmilewitz D, Klein JS, Fiocchi C: Localization of intestinal interleukin 1 activity, protein and gene expression to lamina propria cells. Gastroenterology 1993, 104:749-758

47. Motoike T, Loughna S, Perens E, Roman BL, Liao W, Chau TC, Richardson CD, Kawate T, Kuno J, Weinstein BM, Stainier DY, Sato TN: Universal GFP reporter for the study of vascular development. Genesis 2000, 28:75-81

48. Schlaeger TM, Bartunkova S, Lawitts JA, Teichmann G, Risau W, Deutsch U, Sato TN: Uniform vascular-endothelial-cell-specific gene expression in both embryonic and adult transgenic mice, Proc Natl Acad Sci USA: 1997, 94:3058-3063

49. Kim KK, Kugler MC, Wolters PJ, Robillard L, Galvez MG, Brumwell AN, Sheppard D, Chapman HA: Alveolar epithelial cell mesenchymal transition develops in vivo during pulmonary fibrosis and is regulated by the extracellular matrix, Proc Natl Acad Sci USA 2006, 103:1318013185

50. Zeisberg M, Yang C, Martino M, Duncan MB, Rieder F, Tanjore H, Kalluri R: Fibroblasts derive from hepatocytes in liver fibrosis via epithelial to mesenchymal transition. J Biol Chem 2007, 282:23337-23347

51. Arciniegas E, Sutton AB, Allen TD, Schor AM: Transforming growth factor beta 1 promotes the differentiation of endothelial cells into smooth muscle-like cells in vitro. J Cell Sci 1992, 103:521-529
52. Zeisberg EM, Potenta SE, Sugimoto H, Zeisberg M, Kalluri R: Fibroblasts in kidney fibrosis emerge via endothelial-to-mesenchymal transition. J Am Soc Nephrol 2008, 19:2282-2287

53. Babyatsky MW, Rossiter G, Podolsky DK: Expression of transforming growth factor $\alpha$ and $\beta$ in colonic mucosa in inflammatory bowel disease. Gastroenterology 1996, 110:975-984

54. Wu F, Chakravarti S: Differential expression of inflammatory and fibrogenic genes and their regulation by NF-kappaB inhibition in a mouse model of chronic colitis. J Immunol 2007, 179:6988-7000

55. Rieder F, Brenmoehl J, Leeb S, Scholmerich J, Rogler G: Wound healing and fibrosis in intestinal disease. Gut 2007, 56:130-139

56. Arciniegas E, Frid MG, Douglas IS, Stenmark KR: Perspectives on endothelial-to-mesenchymal transition: potential contribution to vascular remodeling in chronic pulmonary hypertension. Am J Physiol Lung Cell Mol Physiol 2007, 293:L1-L8

57. Potenta S, Zeisberg E, Kalluri R: The role of endothelial-to-mesenchymal transition in cancer progression. Br journal of cancer 2008, 99:1375-1379

58. Scaldaferri F, Vetrano S, Sans M, Arena V, Straface G, Stigliano E, Repici A, Sturm A, Malesci A, Panes J, Yla-Herttuala S, Fiocchi C, Danese S: VEGF-A links angiogenesis and inflammation in inflammatory bowel disease pathogenesis, Gastroenterology 2009, 136: 585-595

59. Roifman I, Sun YC, Fedwick JP, Panaccione R, Buret AG, Liu H, Rostom A, Anderson TJ, Beck PL: Evidence of endothelial dysfunction in patients with inflammatory bowel disease. Clin Gastroenterol Hepatol 2009, 7:175-182

60. Zeisberg EM, Potenta S, Xie L, Zeisberg M, Kalluri R: Discovery of endothelial to mesenchymal transition as a source for carcinomaassociated fibroblasts. Cancer Res 2007, 67:10123-10128

61. Black AR, Black JD, Azizkhan-Clifford J: Sp1 and Kruppel-like factor family of transcription factors in cell growth regulation and cancer. J Cell Physiol 2001, 188:143-160

62. Safe $\mathrm{S}$, Abdelrahim M: $\mathrm{Sp}$ transcription factor family and its role in cancer. Eur J Cancer 2005, 41:2438-2448

63. Duffield JS: Epithelial to mesenchymal transition in injury of solid organs: fact or artifact? Gastroenterology 2010, 139:1081-1083, e1081-1085 